\title{
Psicologia da Educação: uma disciplina em crise no pós-construtivismo
}

\author{
Giovani Ferreira Bezerra \\ Doracina Aparecida de Castro Araujo
}

\begin{abstract}
Resumo
Este ensaio discute a existência de uma crise epistemológica recente na Psicologia da Educação, defendendo a ideia de que o descrédito atual quanto ao paradigma construtivista-cognitivista, de inspiração piagetiana, provocou, no meio educacional, uma reação negativa às contribuições da Psicologia da Educação para a práxis pedagógica e para a formação docente. Em contrapartida, sugere-se a busca por novos fundamentos epistemológicos, que devolvam a esta disciplina seu status científico, de uma perspectiva crítica, reflexiva e emancipadora. Para tanto, a abordagem da Psicologia Histórico-Cultural é apresentada como uma referência básica para se (re)pensar e ensinar, hoje, Psicologia da Educação.
\end{abstract}

Palavras-chave: Psicologia educacional, construtivismo, ensino da psicologia.

\section{Educational Psychology: a post-crisis constructivist subject}

\begin{abstract}
In this study we discuss the existence of an epistemological crisis in recent Educational Psychology and argue that discredit the current paradigm regarding the cognitive-constructivist, inspired by Piaget, provoked a negative reaction to the contributions of Educational Psychology for teaching praxis and for the teacher education. However, it is suggested the search for new epistemological basis, that return to this subject its scientific status from a critical and emancipatory perspective. We present Historical-Cultural Psychology approach as a basic reference for us to (re) think and teach Educational Psychology nowadays.
\end{abstract}

Keywords: Educational Psychology, Constructivism, psychology education.

\section{Psicología de la Educación: una disciplina en crisis en el pós-constructivismo}

\section{Resumen}

Este ensayo discute la existencia de una crisis epistemológica reciente en la Psicología de la Educación. Se defiende la idea de que el descrédito actual sobre el paradigma constructivista-cognitivista, de inspiración piagetiana, provocó, en el medio educacional, una reacción negativa a las contribuciones de la Psicología de la Educación para la práxis pedagógica y para la formación docente. En cambio, se sugiere la búsqueda por nuevos fundamentos epistemológicos que devuelvan a esta disciplina su status científico, de una perspectiva crítica, reflexiva y emancipadora. Para tal efecto se presenta el abordaje de la Psicología Histórico-Cultural como una referencia básica para (re)pensarse y enseñar Psicología de la Educación hoy.

Palabras Clave: Psicología de la Educación, Constructivismo, enseñanza de Psicología. 


\section{Introdução}

Atualmente, temos percebido a existência objetiva de uma crise epistemológica no que se refere à Psicologia da Educação e à sua relação com a Pedagogia. Não é preciso ir muito longe para se constatar que essa disciplina aplicada tem ficado à deriva, exercendo, muitas vezes, uma função decorativa nos cursos de formação de educadores, quando poderia ser um de seus eixos centrais. Nesses termos, a Psicologia da Educação acaba sendo reduzida a uma simples exposição linear de escolas e abordagens psicológicas, de forma a-histórica, descontextualizada e sem a devida análise dos pressupostos filosóficos e sociológicos de cada uma delas, como se valessem em si mesmas. A aplicação de princípios psicológicos à Educação torna-se uma abstração, algo que, no final das contas, pouco interessa ao educador, como instância formativa. Este deve preocupar-se mais com a Didática e com as diversas Metodologias, que "ensinam a dar aulas", "têm utilidade" e revelam uma dimensão mais pragmática do processo educacional. No limite, os estudos em Psicologia seriam importantes na medida em que permitissem aos educadores a identificação de eventuais distúrbios de aprendizagem e algumas receitas para seu "tratamento" em sala de aula.

Como reação contrária a este posicionamento simplista, tem-se observado, entre alguns educadores e pedagogos, certa aversão àquela disciplina, frequentemente acusada de corromper a Educação com modismos psicologizantes. Essa atitude preconceituosa em relação à Psicologia Educacional ${ }^{1}$ tem, entretanto, nos incomodado bastante na qualidade de pesquisadores de linha vigotskiana, comprometidos com o sucesso da práxis pedagógica e com a qualidade da formação docente em todos os seus aspectos, inclusive na dimensão psicológica deste processo. Resolvemos, pois, escrever este ensaio. O trabalho resulta de estudos bibliográficos, realizados nos domínios da Psicologia Histórico-Cultural, em suas interseções com a Pedagogia Histórico-Crítica, bem como de nossas experiências profissionais em escolas de educação básica e no contexto universitário. O intuito é exteriorizar reflexões e inquietudes a respeito dessa problemática, haja vista ser relevante, na atual conjuntura, promover estudos críticos, que busquem entender as raízes da presente crise na Psicologia da Educação.

A confluência das várias pesquisas poderá apontar novos rumos a essa disciplina, porquanto não se trata de negá-la ou considerá-la anacrônica. Antes, é preciso compreender seu verdadeiro papel nas circunstâncias concretas em que vivemos, devolvendo-lhe seu lugar de direito no interior da própria Pedagogia. Com certeza, trata-se de uma tarefa difícil e complexa; mas necessária para repensarmos a permanência de alguns preconceitos, ainda no século XXI, quanto à legitimidade das contribuições da ciência psicológi-

1 Neste ensaio, usaremos os termos Psicologia da Educação, Psicologia Educacional e Psicologia Pedagógica como sinônimos, embora existam alguns teóricos que critiquem o uso de uma ou outra nomenclatura ou ainda defendam outras expressões que melhor denominariam esse ramo da Psicologia. ca para a ciência pedagógica, conquanto não se imagine que uma possa ser reduzida à outra. Sendo educadores, e não psicólogos, apropriando-nos das palavras de Libâneo (1999, p. 83), é conveniente ressaltarmos que "As ideias expostas aqui não formam um pensamento acabado, pelo contrário, devem ser consideradas como uma tentativa muito provisória de estabelecimento das relações entre a Pedagogia e a Psicologia educacional".

\section{As raízes da crise}

Logo de início, lançamos ao leitor a seguinte pergunta: De onde vem esta crise recente, pós-anos 90, nos domínios da Psicologia da Educação e por que ela se intensifica a cada dia, ao pôr em campos opostos psicólogos e pedagogos? Respondendo a essa interrogação, não nos parece equivocado dizer que a origem dessa crise remonta, em larga medida, ao movimento psicopedagógico denominado Construtivismo, bastante hegemônico, no cenário educacional brasileiro, entre os anos 80 e começo dos anos 90 . Esse movimento sugeria que a solução dos problemas pedagógicos estava na Psicologia, embasada, sobretudo, pelas formulações epistemológicas do biólogo e pesquisador suíço Jean Piaget. Naquele contexto, a escola foi transformada em um verdadeiro laboratório experimental, e o trabalho do educador consistia em organizar as melhores condições no ambiente escolar para que a criança construísse seu próprio conhecimento, de acordo com a maturação e o desenvolvimento de seus esquemas mentais. A disseminação dessa abordagem, sem maiores ponderações, acabou se tornando um fetiche na Educação, colocando em segundo plano questões políticas e sociais que persistiam, e ainda persistem, na pauta educacional.

A Psicologia, com ares de neutralidade científica, passou a servir muito bem aos interesses da classe dominante, a burguesia capitalista neoliberal, transformando a objetividade dos problemas estruturais da Educação brasileira em questões particulares e pontuais de distúrbios de aprendizagem dos alunos e inadequação dos conteúdos à sua faixa etária. Assim, ocultavam-se a contento as razões objetivas do fracasso escolar, enquanto ainda se passava a impressão de incríveis avanços no diagnóstico psicopedagógico e na metodologia de ensino, vista como progressista. De fato, naquela época, a intromissão da Psicologia no cotidiano das escolas era tamanha que nem sequer sobrava tempo para o professor efetivamente ensinar: cabia-Ihe classificar hipóteses de escrita dos alunos, identificar estágios do desenvolvimento infantil, realizar atividades de classificação e seriação na sala de aula, aplicar "testes psicológicos" para descobrir o raciocínio espontâneo da criança, seu nível de abstração e assim por diante.

$\mathrm{Na}$ universidade, a situação não era muito diferente. Os acadêmicos dos cursos de Pedagogia precisavam saber todos os períodos "universais" da cognição humana, segundo delimitados por Piaget, com suas respectivas características e intervalos de idade, sem se esquecer de citar palavras 
como assimilação, acomodação, equilibração e adaptação. O psicologismo realmente havia se tornado uma presença constante na formação de educadores, ofuscando a própria Didática e as demais disciplinas de bases estritamente pedagógicas, que viveram, por seu turno, uma crise identitária. Na prática, o resultado do modismo construtivista foi a exacerbação do pragmatismo científico-psicológico. Em nome de ideais alienantes, como o aprender a aprender (Duarte, 2001), chegou-se ao esvaziamento curricular nas escolas, impedindo-se, assim, a efetiva socialização e a democratização do saber objetivo, historicamente produzido e acumulado (Libâneo, 1999; Saviani, 2003). A transmissão legítima dos conteúdos ficou ofuscada. O foco não estava na apropriação dos conhecimentos propriamente dita, mas sim nos processos de sua "construção" individual, na "[...] atividade construtiva dos alunos na realização das aprendizagens escolares" (Coll, Palacios, \& Marchesi, 1996, citado por Duarte, 2001, p. 61); ou, para usarmos aqui um típico jargão construtivista, o principal era a ação do sujeito cognoscente sobre o objeto a ser conhecido.

Desse modo, segundo Santana (2008, p. 170), "[...] o que se verificou no trabalho com as crianças foi uma metodologia do 'espontaneísmo', do 'vamos esperar que a criança compreenda a seu modo, construa seu conhecimento à sua maneira e o coloque em prática'”. Por consequência, conforme denuncia com muita veracidade a autora já citada, "[...] vimos a educação escolar vivenciar momentos de declarada queda de qualidade e se perder em sua prática. Ficou um misto de tradicional com algo vago, sem conteúdo e consistência”. Em parte, a explicação estaria no fato de se extrair diretamente da Epistemologia Genética uma metodologia pedagógica, para aplicação imediata em sala de aula (Santana, 2008). Na esteira dessas considerações, a autora supracitada apresenta, em seguida, uma afirmação fundamental para entendermos o desenrolar da presente crise em torno da Psicologia da Educação. Para ela,

Após várias releituras e a verificação cada vez mais latente de que nossos alunos estão cada vez menos preparados, tanto para a vida acadêmica quanto para o exercício da cidadania e inserção no mercado de trabalho, tal concepção [a construtivista, resultante, sobretudo, das tentativas de se fazer da teoria piagetiana um método], parece ter sido superada (Santana, 2008, p. 170, grifo nosso).

Conquanto a autora não seja categórica em seu posicionamento, pensamos que essa concepção ainda não esteja totalmente superada. Ao contrário, se considerarmos o posicionamento de Duarte (2001) sobre a questão, o Construtivismo acabou ganhando novo fôlego com as apropriações pós-modernas e pós-estruturalistas do pensamento vigotskiano, sob a forma de socioconstrutivismo ou sociointeracionismo. Em publicação mais recente, Duarte (2010) volta a afirmar que, dentre as pedagogias hegemônicas na atualidade, sintetizadas sob o lema do aprender a aprender, a proposta construtivista, com diversas ramificações, permanece atuante. Análises de Rossler (2000, p.
8) também indicam o constante poder de renovação e sedução do ideário construtivista perante os educadores, de modo que "[...] qualquer aparente perda de prestígio para outras teorias seria apenas a expressão de um movimento mais amplo de reorganização e reestruturação teórica do respectivo ideário [...]". Não discordamos, todavia, de que o enfraquecimento daquelas tentativas de aplicação direta da epistemologia piagetiana na práxis educacional tenha alterado, sobremaneira, o universo psicopedagógico.

O insucesso prático delas decorrente, refletido, sobretudo, na queda da qualidade do ensino e no flagrante despreparo dos alunos, segundo cita Santana acima (2008), fez com que os pressupostos psicológicos do trabalho pedagógico fossem questionados quanto à sua pertinência. Nas escolas e no meio acadêmico, o discurso piagetiano, ou explicitamente construtivista-cognitivista, tornou-se insuficiente para explicar as relações entre ensino e aprendizagem. Os novos ajustes do modismo vieram exigir, exatamente, que não se fosse partidário apenas de Piaget, pelo menos em tese. No trabalho educativo, passou-se a considerar que este teórico teria deixado de lado a importância das interações sociais e privilegiado abordagens "espontaneístas" com os alunos, além de apresentar uma explicação muito biológica para a aprendizagem e o desenvolvimento humanos. Devia-se, pois, admitir certa insuficiência do modelo piagetiano, enquanto buscavam-se outros e dilatados referenciais para superar o quadro dramático do ensino. Rosa (1994, citado por Duarte, 1996, p. 88) ilustra bem a situação a que se chegara, reconhecendo ser

[...] preciso admitir uma dificuldade que decorre da própria formulação teórica construtivista, especialmente da versão piagetiana à qual se tem dado maior ênfase. Ao colocar o sujeito como centro e, principalmente, ao vincular a aprendizagem à maturação biopsicológica, Piaget autoriza a inferência de que o processo de aprendizagem ocorre espontaneamente, isto é, independente da ação ou da 'provocação' de um outro sujeito. [...] A esse respeito a teoria de Vygotsky, indubitavelmente, se faz mais clara, ao atribuir especial importância ao meio social, ao adulto educador no processo de aprendizagem.

Nesse contexto, emerge o pós-construtivismo ou construtivismo pós-piagetiano, como um esforço para preencher as lacunas supostamente identificadas na abordagem epistemológica clássica. Saviani (2010, p. 423) dá-nos um exemplo de como os próprios construtivistas se redefiniram. $\mathrm{O}$ autor cita que, perante o avanço das reformas educativas dos anos 90, "Esther Pillar Grossi [uma das principais divulgadoras do Construtivismo no Brasil] também busca situar-se no novo contexto conciliando Piaget com Paulo Freire e introduzindo elementos de Wallon e Vigotski numa proposta que denomina 'pós-construtivismo'”. Em outra passagem, o autor ao realizar um balanço do período compreendido entre 1991-2001, deixa perceber que, ao longo do decênio em tela, teria ocorrido uma metamorfose do Construtivismo, com significativo distanciamento às formulações originais do 
epistemólogo suíço. Nas palavras de Saviani (2010, p. 436), "Nesse discurso neoconstrutivista, tão disseminado nos dias de hoje, são pouco frequentes as menções de estádios psicogenéticos (sensório-motor, pré-operatório, operatório-concreto, operatório-formal”. Essa reformulação ideológica provocou, entre professores da educação básica e até em autores construtivistas, salvo pesquisadores ortodoxos da Epistemologia Genética, certo mal-estar em recorrer, isoladamente, ao referencial piagetiano, que precisava ser completado com as "contribuições" de outros teóricos.

Mediante o exposto, observou-se o fenômeno da "socialização" do Construtivismo, que consistiu em acrescentar a este ideário maior ênfase nas trocas sociais e nos processos intersubjetivos (Duarte, 1996). No senso comum pedagógico, imaginava-se, então, superar as "limitações" do modelo interacionista mais dogmático, fundamentado, principalmente, na determinação biológica do conhecimento. Vale ressaltar, entretanto, que a tese segundo a qual Piaget desconsiderara as interações sociais revelou-se, por meio de análise científica mais acurada, produto de um equívoco na interpretação de seus postulados. Os pós-construtivistas, os quais muitas vezes se autodenominam vigotskianos, começaram a enfatizar a ausência do social na obra piagetiana, com o fito de justificar suas posições ecléticas. Mas, para Duarte (1996, p. 257), esse procedimento seria desnecessário, porquanto "[...] o construtivismo piagetiano já contém um modelo do social e esse modelo se respalda no modelo biológico entre organismo e meio ambiente". Todavia, para contornar as críticas endereçadas ao cognitivismo "puro", muitos estudiosos, aderindo ao reformismo construtivista, vêm recorrendo às proposições vigotskianas. Aparentemente críticos,

Esses autores procuram em Vigotski algo que não pode ser encontrado no autor russo, mas que está em Piaget. Esses autores são piagetianos sem o admitir e compartilham com o pensador suiço o modelo sociointeracionista ou, o que é equivalente, o modelo interacionista do social (Duarte, 2001, pp. 257-258).

Tal situação, que esteve em voga com mais evidência a partir de meados dos anos 90, projetando-se para a primeira década do século XXI, foi, a nosso ver, a principal responsável pelo esvaziamento da disciplina Psicologia da Educação nos cursos de Pedagogia. Se não mais se devia ensinar Piaget como principal referência do trabalho psicopedagógico, o que se ensinaria? Sem a segurança do antigo paradigma cognitivista, as universidades ficaram perdidas; deixaram-se levar pela nova onda reformista, ora tratando as questões psicológicas do processo educacional com certo desprezo, ceticismo e antipatia; ora defendendo abordagens tão ecléticas que predominava a superficialidade conceitual e metodológica. Nessa onda, encontramo-nos mergulhados ainda hoje, em maior ou menor escala, confusos com o "[...] misto de tradicional com algo vago, sem conteúdo e consistência" (Santana, 2008, p. 170). Diante das circunstâncias, o pragmatismo parece a alternativa mais recorrente.
Não podemos negar, entretanto, a ocorrência de algumas tentativas no sentido de dar novos rumos à Psicologia Educacional, especialmente com a divulgação da teoria vigotskiana em nosso país. Esta vem ganhando boa expressividade nas escolas e universidades brasileiras, desde os anos 90, conforme se pôde depreender das próprias citações reproduzidas anteriormente. Contraditoriamente, porém, a divulgação da Psicologia Histórico-Cultural, que tem em Vigotski ${ }^{2}$ um de seus principais expoentes, acabou por tornar a mencionada crise ainda mais aguda e persistente. A recepção desse autor no meio educacional foi marcada pela incompreensão de sua obra, lida de forma superficial e descontextualizada; pela supressão dos princípios marxistas que nortearam toda a sua produção científica e pelo ecletismo na interpretação de seus pressupostos teóricos (Duarte, 2001; Tuleski, 2008). Em decorrência disso, Vigotski facilmente foi e é incorporado ao relativismo epistemológico dos paradigmas da pós-modernidade (Duarte, 2001), inclusive à variante "pós-construtivista" do ideário construtivista.

Tal fato tem dificultado contribuições mais significativas desse autor para nossas expectativas contemporâneas, tanto no que se refere à articulação de novos referenciais psicológicos para a formação de educadores nos cursos de licenciatura, quanto ao fazer pedagógico stricto sensu. Quando vistos pelo ângulo do discurso neoconstrutivista, desprovidos da historicidade em que foram propostos, também os conceitos vigotskianos representam apenas mais do mesmo, pelo que acabam resultando estéreis, do ponto de vista revolucionário. Além do mais, não podem, em si mesmos, solucionar os problemas educacionais herdados dos anos anteriores. Na verdade, tais conceitos encerram um potencial reflexivo para pensarmos, coletivamente, a transformação das circunstâncias educacionais hodiernas, o que, à luz da teoria vigotskiana, é inseparável do combate à sociedade capitalista, em suas diversas formas de mutilação psicológica, exploração econômica e reificação da consciência. Como nem sempre essas ponderações e limites têm sido levados em conta, a Psicologia da Educação, quando tenta renovar-se, por meio da concepção histórico-social do psiquismo, continua sem uma saída consistente para reafirmar sua identidade, nos cursos de Pedagogia.

Mas, então, onde está a saída para tal crise? Onde procurá-la? Tratar-se-ia de retornar às concepções de Piaget, visto que, nos anos 80 e início dos anos 90, ao menos se tinha um referencial mais sólido e explícito para a condução da Psicologia Educacional e se estudava, em pormenores, o desenvolvimento cognitivo da criança, tomado como a sucessão progressiva de estágios psicológicos? Por certo que não. Se concordássemos com semelhante argumentação, estaríamos defendendo a volta ao psicologismo reducionista que marcou aquelas décadas e desnorteou ainda mais nossas escolas, a ponto de acentuar o rebaixamento do nível de ensino nelas praticado, conforme já dito. Para superar o

2 O nome desse autor aparece grafado de diversas maneiras. No corpo do texto e nas referências bibliográficas, manteremos a grafia original, conforme a fonte citada. Nos demais casos, usa-se Vigotski. 
impasse, trata-se, inicialmente, de reconhecermos a herança negativa que o Construtivismo piagetiano, mal aplicado, legou à Psicologia da Educação, resgatando-se a importância desta para constituição da ciência pedagógica, sob um referencial desmistificado. Entendemos que, se o desejo é a formação plena do educador para o conhecimento de si e dos futuros alunos como seres sócio-históricos, "O problema não reside portanto em trazer o social para o construtivismo, mas em buscar outro modelo epistemológico, diferente do modelo biológico que está na base do interacionismo-construtivista" (Duarte, 1996, p. 89).

Nesse aspecto, acreditamos que as formulações teóricas de Vigotski, quando não deturpadas e preservadas em sua intencionalidade original, revelam-se bastante oportunas, vislumbrando possibilidades transformadoras para se pensar, hoje, os processos pedagógicos que levam à constituição psicológica do homem, mesmo no interior de relações capitalistas de produção. Em sua tentativa de construir uma Psicologia marxista, capaz de responder aos anseios da sociedade socialista que começava a se constituir na da Rússia pós-revolucionária dos anos 20 e 30 do século $X X$, esse psicólogo deparou-se também com um momento profundamente crítico na Psicologia de seu país ${ }^{3}$. Naquele momento, a intelectualidade russa, reproduzindo uma tendência mundial, estava basicamente dividida entre defensores de teorias idealistas e defensores de teorias materialistas (Tuleski, 2008; Vigotski, 1982/2004a), o que lançava muitas dúvidas sobre a legitimidade das conclusões psicológicas obtidas em semelhante conjuntura. Para Vigotski, entretanto, isso não era motivo para desacreditar in totum a Psicologia como uma ciência objetivamente válida. Em suas palavras, "A crise é destruidora, mas benéfica: nela se oculta o auge da ciência, seu enriquecimento, sua força, e não a impotência e a falência" (Vigotski, 1982/2004a, p. 324).

Em meio àquele caos científico que se instaurara entre os pensadores e pesquisadores russos de seu tempo, o autor conseguia enxergar uma oportunidade para encontrar novos fundamentos teórico-metodológicos para reconstituir as bases conceituais da Psicologia, de uma perspectiva não reducionista, qualitativamente superior. Naquelas condições, uma das tarefas mais urgentes que se colocava para Vigotski era justamente uma revisão crítica dos conceitos da Psicologia Educacional, que ele preferia chamar de Psicologia Pedagógica (Vigotski, 1982/2003). Para ele, tal revisão não significava de modo algum depurar a Pedagogia de qualquer influência psicológica, mas sim tinha como principal objetivo restabelecer a necessária unidade dialética entre a investigação psicológica e a prática pedagógica cientificamente fundamentada (Vigotski, 1982/2003). Na perspectiva vigotskiana,

3 Em quase todos os seus textos, Vigotski deixa transparecer, explícita ou implicitamente, a existência de uma grave crise na ciência psicológica em princípios do século $X X$, que atingia com especial intensidade a frágil Psicologia russa e soviética. No texto O significado histórico da crise da Psicologia: uma investigação metodológica, escrito em 1927, disposto na coletânea Teoria e Método em Psicologia, o autor aborda diretamente essa questão, fornecendo-nos uma perspectiva para se pensar o nosso presente.
[...] renunciar à psicologia na hora de elaborar um sistema educativo significaria renunciar a toda possibilidade de explicar e fundamentar cientificamente o próprio processo educativo, a própria prática do trabalho pedagógico. [...]. Significaria prescindir dos alicerces na hora de construir a educação e prescindir de um elo de conexão entre as múltiplas e variadas disciplinas metodológicas e pedagógicas. Falando claramente, renunciar à psicologia significa renunciar à pedagogia científica (Vigotski, 1982/2003, p. 150).

Vigotski não poderia ser mais claro nessa citação! O autor mostra de forma eloquente que não podemos simplesmente ignorar ou rejeitar, em absoluto, as contribuições da Psicologia na Educação. Sem esta, a Pedagogia perderia, para o autor, a cientificidade e cairia no senso comum, tornando-se, no máximo, uma arte aplicada, sem um planejamento consciente, rigoroso e intencional quanto aos meios e fins a serem mobilizados na práxis educacional. Por outro lado, também precisaríamos da Psicologia como uma mediadora constante entre as várias disciplinas metodológicas e pedagógicas, garantindo-se a unidade, e não a fragmentação do trabalho educativo. O posicionamento de Vigotski, cabe ressaltar, nada tem a ver com o psicologismo do modelo interacionista-construtivista. Muito pelo contrário! Para explicar melhor esta afirmativa, reproduzimos um trecho relativamente longo, mas esclarecedor, no qual esse psicólogo explicita, com precisão, a defesa que fazia, na Rússia soviética, sobre a devida "reestruturação das ideias psicológicas” (Vigotski, 1982/2003, p. 150), tão necessária para ele. De acordo com o autor supracitado:

[...] a nova psicologia é um fundamento para a educação em uma medida muito maior do que o era a psicologia tradicional [...]. O novo sistema não precisará se esforçar para extrair de suas leis as derivações pedagógicas nem adaptar suas teses à aplicação prática na escola, porque a solução para o problema pedagógico está contida em seu próprio núcleo teórico, e a educação é a primeira palavra que menciona. Por conseguinte, a própria relação entre psicologia e pedagogia mudará de modo considerável, sobretudo porque aumentará a importância que cada uma tem para a outra e desenvolver-se-ão, portanto, os laços e o apoio mútuo entre as duas ciências (Vigotski, 1982/2003, p. 151, grifo nosso).

A perspectiva vigotskiana, conforme o excerto, toma como pressuposto básico a reciprocidade no relacionamento entre Psicologia e Pedagogia, sem que uma anule ou negue a outra. Esta é a tese que também defendemos, no momento atual, como proposta para se fortalecer a formação inicial do pedagogo, chegando-se, assim, à definição positiva dos papéis doravante assumidos pela Psicologia da Educação. Dentre esses papéis, espera-se que ela possibilite ao futuro educador "[...] uma base para falar do significado exato da tarefa educativa e das leis científicas que a regem, em vez de falar sobre conjeturas e metáforas" (Vigotski, 1982/2003, p. 150). Para tanto, acreditamos que não basta apenas reconhecer a legitimidade do saber psicológico em relação ao 
saber pedagógico e vice-versa, usando-nos tão somente de belas "metáforas e conjeturas", que rapidamente caem no vazio. Como adverte Vigotski (1982/2004a, p. 324, grifo nosso), "Não é possível realizar um trabalho psicológico sem estabelecer os princípios fundamentais dessa ciência. Antes de iniciar a construção, é preciso colocar os alicerces".

$\mathrm{Na}$ busca por tais alicerces, parece-nos de extrema relevância que a Academia, assumindo incontinenti essa tarefa, se coloque diante de um problema essencial, de viés crítico, sem o que não acreditamos ser possível avançar, de modo significativo, na resolução da supracitada crise: o problema da competência técnica e do compromisso político (Saviani, 2003) no ensino contemporâneo de Psicologia Educacional nas universidades brasileiras. Com a discussão realista dessa tese, torna-se viável pensar outras possibilidades e sentidos para a referida disciplina acadêmica; ao mesmo tempo, acredita-se ser possível a explicitação dos novos desafios que ela deve assumir para recuperar seu status científico nos cursos de Pedagogia, exercendo um papel mediador na formação crítica dos futuros educadores. Logo, cabe-nos explicar qual o significado atribuído, neste ensaio, aos termos competência técnica e compromisso político, quando vinculados à Psicologia da Educação. A priori, deve-se ter em mente que não tratamos de aspectos dicotômicos, mas de dimensões inseparáveis do mesmo compromisso.

\section{A competência técnica e o compromisso político em Psicologia da Educação}

Para que a Psicologia da Educação seja reabilitada como uma disciplina basilar da licenciatura em Pedagogia, convertendo-se no "[...] elo de conexão entre as múltiplas e variadas disciplinas metodológicas e pedagógicas", conforme expressão de Vigotski (1982/2003, p. 150), é imprescindível que ofereça, ao acadêmico, um conjunto de saberes teórico-práticos e metodológicos consistentes; saberes capazes de orientar e subsidiar sua práxis pedagógica de maneira objetiva e não reducionista, sem que a especificidade dessa práxis seja diluída em tergiversações psicologizantes e fetichizadas. É, pois, nesse conjunto de saberes que situamos a competência técnica no universo da Psicologia da Educação. Dito de outro modo, não podemos negar a necessidade premente que tem o futuro educador de conhecer sistematicamente o desenvolvimento infantil, em suas diversas características ontogenéticas e manifestações cognitivas, afetivas e psicossociais, além de possíveis estratégias de intervenção nesse desenvolvimento, tal como este é abordado em diversas escolas psicológicas. Ao conhecê-las, os futuros professores terão melhores condições para planejar e avaliar o conteúdo a ser ministrado em suas aulas, bem como para direcionar, com mais propriedade, o processo de ensino e aprendizagem dos alunos, rechaçando posições ecléticas e reacionárias, favoráveis à manutenção do status quo dominante.
Em si mesma, porém, a competência técnica não basta. Antes, pode até conduzir a equívocos lamentáveis, produzindo a figura decepcionante do "[...] idiota especializado, competente formalmente, tapado politicamente" (Demo, 2006 , p. 36, grifo do autor). Afinal, para que serve estudarmos a teoria de Piaget, de Vigotski ou de qualquer outro eminente psicólogo, se não conseguirmos fazer uma leitura crítica e histórica de suas concepções, se não conseguirmos vislumbrar a ideologia que cada um defende, direta ou indiretamente, para, e só então, tomarmos um partido pessoal? Para que acumularmos inúmeros conceitos e jargões psicológicos, se nem sequer nos dermos conta da concepção de homem, criança e sociedade que cada um adota em seus pressupostos filosóficos? Sem a mediação dessa leitura crítica e totalizante, corremos o risco de continuar legitimando e adotando concepções que fazem da Psicologia uma ferramenta de naturalização do indivíduo; este tomado como um ente interativo abstrato, a-histórico, dotado de esquemas cognitivos universais, que estão buscando constantemente adaptar-se a uma realidade transitória (Duarte, 2001).

Diante disso, vem à tona a questão do compromisso político daquele que ensina a disciplina Psicologia da Educação, seja ele um pedagogo ou um psicólogo, haja vista que, no entender de Pedro Demo (2006, p. 107), "O profissional competente se realiza em dois horizontes mais marcantes: como capaz de operar a instrumentação científica em termos de aplicação prática [o que, no nosso caso, significa o domínio objetivo do saber psicopedagógico em sua vinculação concreta com as demandas do fazer pedagógico] e como capaz de ser ator eficaz na realidade histórica". Explicando melhor, o profissional responsável pelo ensino de Psicologia da Educação, além de apresentar competentemente os fundamentos psicológicos do trabalho pedagógico, deverá proporcionar, ao pedagogo em formação, condições básicas para a emergência de uma reflexão honesta. Reflexão para se pensar sobre os determinantes sócio-históricos e políticos que marcaram, e continuam marcando, a constituição de todas as abordagens psicológicas; reflexão para se evidenciar a proximidade destas com a alienação ou com a emancipação do homem, com a reprodução da sociedade de classes ou com a sua negação revolucionária. Nessa direção, pensamos serem oportunas as contribuições da Psicologia Histórico-Cultural, representada por Vigotski, autor supracitado, além de outros psicólogos, como Luria e Leontiev, talvez menos conhecidos no Brasil.

A defesa explícita que fazemos de tal abordagem tem uma justificativa. Tendo nascido do desejo concreto de homens concretos pela superação da sociedade burguesa, em todos os seus antagonismos sociais, econômicos e psicológicos, ela encerra grandes possibilidades para se conhecer, de maneira dialética e historicizante, as contradições da Psicologia e da consciência humana; especialmente no interior de uma sociedade capitalista como a atual, que, descaradamente, tem cultivado um tipo de indivíduo alienado, egocêntrico e passivo, incluindo-se aí, quase sempre de modo involuntário ou inconsciente, o educador, estranhado de sua própria individualidade. Há uma afirmação de Luria 
que traduz, em plenitude, o significado emancipatório que a concepção Histórico-Cultural atribui à consciência humana. Nos dizeres desse autor,

Alinhando-se com o pensamento de Marx e Lenin, a psicologia soviética [ou seja, Histórico-Cultural], sustenta que a consciência é a forma mais elevada de reflexo da realidade: ela não é dada a priori, nem é imutável e passiva, mas sim formada pela atividade e usada pelos homens para orientá-los no ambiente, não apenas adaptando-se a certas condições, mas também reestruturando-se (Luria, 1974/2002, p. 23, grifo do autor).

Dessa perspectiva, acreditamos que o conceito de consciência, sendo esta compreendida como formação sócio-histórica e ativa do psiquismo humano (Leontiev, 1959/1978; Luria, 1974/2002), passe a ocupar um lugar de destaque nas aulas e discussões sobre a Psicologia da Educação. Entendemos que os acadêmicos precisam, como um carecimento de primeira ordem, tomar conhecimento de si mesmos, de sua personalidade, a fim de conquistarem o domínio volitivo sobre seu comportamento, suas ações e suas funções psicológicas superiores, tipicamente humanas (Vigotski, 1978/2008). Assim, poderão ascender, paulatinamente, a uma relação consciente, minimamente alienada, com sua própria individualidade, tornando-a, tanto quanto posível, uma individualidade para-si (Duarte, 1993), sob a qual será possível a formação do novo homem (Vigotski, 1982/2004a; Vygotsky, 1930/2004b), do novo educador, "[...] liberto até o desenvolvimento completo e harmonioso de todas as suas aptidões e propriedades" (Leontiev, 1959/1978, p. 142). A tomada de consciência, processo longo e dramático, a ser ao menos iniciado durante a graduação em Pedagogia, como exigência precípua para se concretizar aí o compromisso técnico-político da Psicologia Pedagógica, é passo inicial para que os futuros pedagogos reconheçam sua condição histórica de sujeitos.

Sujeitos globalizados, imersos em um sistema econômico mundial, que, dia a dia, os expropria não apenas materialmente, mas também intelectualmente, provocando o fenômeno da consciência desintegrada (Leontiev, 1959/1978). Uma consciência fragmentada, desarticulada e alienada, perdida em meio às incertezas pós-modernas, contra as quais os professores terão que duelar sem descanso, para exercerem, plenamente, a autoria de sua práxis (Santana, 2008), sem sucumbir ao jugo perverso do capital. Como lembra Vigotski, "Tomar consciência significa, em certa medida, dominar" (Vygotski, 1983/1997, p. 268, tradução nossa), mas não só o nosso ser individual. Antes, trata-se de dominar a própria História da sociedade, o curso de suas transformações qualitativas rumo a uma existência humana mais livre e universal, mediada pelo conhecimento psicológico que se tem de homem e de criança enquanto seres dotados de historicidade e singularidade concretas; não como criaturas abstratas, condenadas a uma adaptação conformista às circunstâncias de vida.
Esta é parte importante do caminho a ser trilhado, hoje, para a superação da crise instaurada na Psicologia da Educação, conquanto se tenha como objetivo a formação de um novo homem, reconhecido pela sua integridade psíquica e capacidade de determinação social (Vygotski, 1930/2004b). Para tanto, competência técnica e compromisso político precisam figurar como instâncias de um mesmo processo, dialeticamente interligadas. O enfrentamento da situação ora descrita exige, pois, uma Psicologia Pedagógica que vá além de descrições simplistas e corriqueiras sobre o desenvolvimento infantil, evoluindo-se para uma crítica da Psicologia e dos modelos psicológicos que tentam explicar tal desenvolvimento. Essa crítica, entretanto, não se esgota em si mesma, mas tem o intuito declarado de fazer com que o educador, formado e em formação, vá se apropriando da verdade sobre si mesmo e sobre a sociedade como um todo. O objetivo é propiciar aos docentes mediações teóricas para levá-lo à reapropriação de sua consciência, de sua condição como ser social e histórico, bem como de suas potencialidades para a coordenação autônoma e reflexiva do fazer pedagógico. Um fazer que, sendo práxis, aparece inseparável do saber psicológico, especialmente quando este é tomado não mais de uma perspectiva alienante, porém sob o ponto de vista formativo, intencional e, portanto, conhecido em seus limites e possibilidades.

Já finalizando este texto, gostaríamos de deixar registrada uma última citação de Vigotski. O trecho é relevante, porquanto sintetiza claramente esses novos objetivos e tarefas não só da ciência psicológica em toda a sua extensão, como também, pari passu, da Psicologia da Educação, na presente luta travada pela reafirmação de sua identidade no interior da Pedagogia. Conforme o autor, "Ser[mos] donos da verdade sobre a pessoa e sobre a própria pessoa é impossível enquanto a humanidade não for dona da verdade sobre a sociedade e da própria sociedade" (Vigotski, 1982/2004a, 417). Sem dúvida, isso confere, também nos nossos dias conturbados, uma dimensão emancipatória e libertadora à Psicologia Educacional. Eis o grande desafio contemporâneo nesse campo de saberes, para cujo enfrentamento deverão tender todos os nossos esforços, sejamos pedagogos ou psicólogos.

\section{Considerações Finais}

Ao longo deste texto, polemizamos a respeito da existência de uma crise epistemológica recente, sofrida pela Psicologia da Educação, nas escolas e universidades brasileiras. Isso não significa que outros momentos críticos não tenham existido, tampouco que este ensaio tenha a pretensão de esgotar o assunto. Apontamos como a causa básica dessa crise a atual falência, no meio educacional, do modelo construtivista-cognitivista, de inspiração marcadamente piagetiana, embora seja necessário empreender pesquisas bibliográficas de maior abrangência para se apresentar um panorama mais detalhado das flutuações sofridas, nas últimas décadas, pela Psicologia Educacional. Muito em voga 
no Brasil durante os anos 80 e 90, agora, no século XXI, tal modelo tem repercutido de forma negativa junto à boa parcela de professores e pesquisadores em educação, identificado como uma tendência psicologizante e não crítica. Em decorrência disso, aquela disciplina, em nossa análise, teria ficado bastante desacreditada. Por ter sido umas das principais portas de entrada e divulgação do Construtivismo no citado período, a Psicologia da Educação, com os impactos negativos legados por essa abordagem, vem perdendo sua importância nos cursos de formação de educadores, ou mesmo sendo duramente questionada.

Sem um novo referencial teórico para ocupar o lugar deixado pela queda da Epistemologia Genética, cogitamos a hipótese de que a crise teria se agravado ainda mais, a despeito de algumas tentativas, malsucedidas, de se recorrer à abordagem histórico-cultural para preencher o "vazio". O fracasso dessas tentativas, conforme apontamos rapidamente, deu-se pelo fato notório de que as ideias vigotskianas foram - e ainda são - mal compreendidas, deslocadas de sua significação revolucionária contextual e, na maioria das vezes, confusamente misturadas ao antigo paradigma, reajustado como socioconstrutivismo. Apesar da fecundidade teórico-metodológica existente na escola soviética, esta pouco tem contribuído para afastar os preconceitos da Academia e das escolas em relação à validade das contribuições da Psicologia Educacional à práxis pedagógica. A despeito do que esperam muitos educadores, a concepção histórico-cultural também não pode dar respostas imediatas aos problemas escolares, muito menos mantidas as relações sociais capitalistas, contra as quais se opõe por princípio Sua principal contribuição é mediar a luta pela transformação revolucionária dessas relações. No âmbito do pós-construtivismo, como se tem denominado as tentativas ecléticas de conciliar Piaget e Vigotski, entre si e com outras correntes psicológicas, novas frustrações tendem a ocorrer, porque o problema permanece latente na base.

Diante do impasse descrito, tentamos, neste ensaio, resgatar, ainda que de passagem, o significado original e crítico de algumas formulações de Vigotski, no sentido de revelarmos a importância que esse autor atribuía explicitamente ao papel da Psicologia na Educação. Como uma possível saída dessa crise, apontamos a articulação de novos referenciais para o ensino de Psicologia da Educação nas universidades. Referenciais que, por sua vez, sejam capazes de proporcionar aos futuros educadores uma relação consciente consigo mesmos, com sua individualidade e com as demandas de seu trabalho (psico)pedagógico. Defendemos a necessidade de se existir, no trabalho acadêmico com essa disciplina, a imprescindível mediação da competência técnica e do compromisso político. A fim de assegurar a efetividade da mediação anunciada, demos relevo especial para as contribuições da Psicologia Histórico-Cultural. Esta abordagem psicológica, longe de dar "fórmulas prontas", suscita uma discussão ampla e objetiva acerca da consciência humana e das perspectivas para sua emancipação, partindo-se da crítica à organização social capitalista.
Com certeza, as reflexões ora apresentadas não foram tão longe quanto gostaríamos e podem mesmo ser consideradas introdutórias e singelas, dada a urgência que sentíamos em abordar a problemática apontada neste ensaio. As ideias expostas carecem, ainda, de serem complementadas e melhor sistematizadas em trabalhos futuros, com estudos mais abrangentes, realizados por nós ou outros pesquisadores, interessados no assunto. Pensamos que, de algum modo, as reflexões de nossa autoria possam contribuir, ao menos como ponto de partida, para o reconhecimento e superação da atual crise em torno da Psicologia da Educação; com a consequente busca pelo desenvolvimento de novos fundamentos teórico-metodológicos em torno dessa disciplina e suas implicações para a práxis educacional. Esperamos, sobretudo, que ela não seja negligenciada pela Pedagogia, mas aí reconquiste seu espaço na formação crítico-reflexiva do pedagogo, do novo homem, opondo-se às diversas formas de alienação social e psíquica presentes na sociedade capitalista hegemônica.

\section{Referências}

Demo, P. (2006). Pesquisa: princípio científico e educativo (12a ed.). São Paulo: Cortez.

Duarte, N. (1993). A individualidade para-si: contribuições a uma teoria histórico-social da formação do indivíduo. Campinas, SP: Autores Associados.

Duarte, N. (1996). Educação escolar, teoria do cotidiano e a escola de Vigotski. Campinas, SP: Autores Associados.

Duarte, N. (2001). Vigotski e o "aprender a aprender": crítica às apropriações neoliberais e pós-modernas da teoria vigotskiana (2a ed. ver. amp.). Campinas, SP: Autores Associados.

Duarte, N. (2010). O debate contemporâneo das teorias pedagógicas. Em L. M. Martins \& N. Duarte (Orgs.), Formação de professores: limites contemporâneos e alternativas necessárias (pp. 33-49). São Paulo: Cultura Acadêmica.

Leontiev, A. N. (1978). O desenvolvimento do psiquismo (M. D. Duarte, Trad.). Lisboa: Livros Horizonte. (Trabalho original publicado em 1959)

Libâneo, J. C. (1999). Democratização da escola pública: a pedagogia crítico-social dos conteúdos (16a ed.). São Paulo: Loyola,

Luria, A. R. (2002). Desenvolvimento cognitivo: seus fundamentos culturais e sociais (L. M. Barreto, M. K. de Oliveira, M. M. M. de Andrade \& R. H. Maciel, Trads.) (3a ed.). São Paulo: Ícone. (Trabalho original publicado em 1974)

Rossler, J. H. (2000). Construtivismo e alienação: as origens do poder de atração do ideário construtivista. Em N. Duarte (Org.), Sobre o construtivismo: contribuições a uma análise crítica (pp. 3-22). 
Campinas, SP: Autores Associados.

Santana, M. S. R. (2008). A prática pedagógica como autoria. Em D. A. de C. Araujo (Org.), Pesquisa em Educação: inclusão, história e política (pp. 169-180). Campo Grande: UCDB.

Saviani, D. (2003). Pedagogia Histórico-Crítica: primeiras aproximações (8a ed.). Campinas, SP: Autores Associados.

Saviani, D. (2010). História das ideias pedagógicas no Brasil (3a ed. rev.). Campinas, SP: Autores Associados.

Tuleski, S. C. (2008). Vygotsky: a construção de uma Psicologia Marxista (2a ed.). Maringá, PR: EDUEM.

Vygotski, L. S. (1997). Obras escogidas V: fundamentos de defectología (J. G. Blank, Trad.). Madrid: Visor. (Trabalho original publicado em 1983)

Vigotski, L. S. (2003). O desenvolvimento psicológico na infância
(C. Berliner, Trad.). São Paulo: Martins Fontes. (Trabalho original publicado em 1982)

Vigotski, L. S. (2004a). Teoria e Método em Psicologia (C. Berliner, Trad.) (3a ed.). São Paulo: Martins Fontes. (Trabalho original publicado em 1982)

Vygotsky, L. S. (2004b). A transformação socialista do homem (N. Dória, Trad.). URSS: Varnitso. Recuperado: 6 set. 2009. Disponível: http://www.marxists.org/portugues/vygotsky/1930/ mes/transformacao.htm. (Trabalho original publicado em 1930)

Vigotski, L. S. (2008). A formação social da mente: o desenvolvimento dos processos psicológicos superiores (J. Cipolla Neto, L. S. M. Barreto \& S. C. Afeche, Trads.) (7a ed.). São Paulo: Martins Fontes. (Trabalho original publicado em 1978)

\section{Sobre os autores}

Giovani Ferreira Bezerra (gio_bezerra@hotmail.com)

Pedagogo pela Universidade Estadual de Mato Grosso do Sul (UEMS), unidade universitária de Paranaíba - MS. Mestrando em educação pela UEMS/unidade de Paranaíba. Endereço: Rua Travessa X, 75, Bairro Jardim Daniel I, Paranaíba- MS, CEP 79500-000.

Doracina Aparecida de Castro Araujo (doracina@uems.br)

Doutora em Educação pela Universidade Estadual de Campinas (UNICAMP). Coordenadora e docente do Programa de Pós-Graduação Stricto Sensu em Educação, docente nos cursos de Pós-Graduação Lato Sensu em Direitos Humanos e em Educação e de graduação em Pedagogia na Universidade Estadual de Mato Grosso do Sul (UEMS), unidade universitária de Paranaíba. Líder do Grupo de Estudos e Pesquisas em Práxis Educacional (GEPPE) e coordenadora da linha de Pesquisa Educação Escolar Inclusiva. Endereço: Universidade Estadual de Mato Grosso do Sul. Unidade Universitária de Paranaíba. Av. Vereador João Rodrigues de Mello, s.n., Jardim Santa Mônica, Paranaíba-MS. CEP: $79500-000$. 